\title{
EPIDEMIOLOGY OF KELOIDS AND HYPERTROPHIC SCARS IN A TERTIARY CARE TEACHING HOSPITAL OF NORTHERN INDIA
}

\section{Plastic Surgery}

Dr Bharat Mishra

Classified Specialist (Surgery) \& Plastic Surgeon Department of Plastic Surgery, Army Hospital R \& R, Delhi Cantt, New Delhi - 110010

\section{Dr Chetna Arora*}

Classified Specialist (Community Medicine), C/o Lt Col Bharat Mishra, Plastic Surgeon, Department of Plastic Surgery, Army Hospital R \& R, Delhi Cantt, New Delhi $110010 *$ Corresponding Author

\begin{abstract}
\section{BACKGROND}

Keloids and hypertrophic scars are benign dermal fibro-proliferative characterized by an uncontrolled proliferation of fibrous tissue. They are more common in dark skinned people and certain areas are more prone for pathological scarring. This study was conducted to find the epidemiology of keloids and hypertrophic scarring in outdoor patients of Plastic Surgery department of a tertiary care teaching hospital. METHODS This study was conducted in the a tertiary teaching hospital of Northern India, over a period of 18 months. The prospective study included all patients presenting to the plastic surgery OPD with keloids and hypertrophic scars. RESULTS One hundred seven patients (39 females and 68 males) with mean age 35.68 year were included. Pre sternum was the most common site, followed by torso, back and extremities. The most common cause was trauma (including minor trauma) which was found in 29 patients followed by post infective origin in 22 patients. Pain was not a major complaint most of the patients complained of pruritis. CONCLUSION This, an epidemiological study, was carried out in a tertiary hospital of northern India. The keloids and hypertrophic scars are more common in young males and most common cause being trauma and most commonly affected site is Pre-sternum. Itching is a common complaint though localized pain was complained by a few patients only.
\end{abstract}

\section{KEYWORDS}

Hypertrophic scars, keloids, epidemiology, etiology

\section{INTRODUCTION}

Keloids and hypertrophic scars are dermal fibro-proliferative, benign disorders unique to humans that are characterized by an uncontrolled proliferation of fibrous tissue that can occur following trauma, inflammation, surgery, sometimes spontaneously. The keloid is defined as an abnormal scar that grows beyond the boundaries of the original site of skin injury.1 Alibert used the term "cheloide", derived from the Greek "chele" or crab claw to describe the lateral growth of tissue int

\section{Methodology}

The study was conducted in the Department of Plastic Surgery of a tertiary teaching hospital of Northern India, over a period of 18 months. The prospective study included all patients presenting to the plastic surgery OPD with keloids and hypertrophic scars. A detailed medical history and examination of each patient was done along with emphasis on duration of scars and initial injury giving rise to keloid and hypertrophic scar formation. Detailed recording of demographic parameters like age, sex, site of lesion was done. These details were recorded. Data were tabulated and presented as results in tabular form.

\section{Results:}

\section{Age Distribution}

One hundred seven patients participated in the study. The patients were in the range of 4 years to 79 years of age. The mean age was 35.68 years

\section{Sex Distribution}

In the study $39(35.5 \%)$ were females while $68(63.5 \%)$ were males. Male to female ratio was 1.74:1.

\section{Scar Distribution}

There were total of 143 scars. Single scar was present in $88(82.2 \%)$ patients, while multiple scars were found in $19(17.8 \%)$ patients

Table 1. Scar distribution

\begin{tabular}{|c|c|c|}
\hline No. of scars & No of patients & Percentage \\
\hline One & 88 & 82.3 \\
\hline Two & 13 & 12.1 \\
\hline More than Two & 6 & 5.6 \\
\hline
\end{tabular}

\section{Scarlocation}

Pre sternum was the most common site, followed by torso, back and extremities.

\section{Table 2. Location of scar}

\begin{tabular}{|c|c|c|}
\hline Scar location & Number of patients & Percentage \\
\hline Pre sternal & 61 & 57.1 \\
\hline Torso and Back & 24 & 22.4 \\
\hline Extremities & 12 & 11.2 \\
\hline Face and Neck & 10 & 9.3 \\
\hline
\end{tabular}

\section{Etiology of scars}

The most common cause being trauma (including minor trauma) which was found in 29 patients $(27 \%)$ followed by post infective origin in $22(20.6 \%)$ patients.

\section{Table 3. Etiology of scars}

\begin{tabular}{|c|c|c|}
\hline Etiology of Scar & Number of patients & Percentage \\
\hline Post-Trauma & 29 & 27.1 \\
\hline Post-Infection & 22 & 20.6 \\
\hline Spontaneous & 21 & 19.6 \\
\hline Post-Surgery & 19 & 17.8 \\
\hline Post - Burns & 16 & 14.9 \\
\hline
\end{tabular}

\section{Scar Assessment}

\section{Volume of scar (mm3)}

The scars were assessed for the size in terms of volume. Total volume was $738 \mathrm{~cm} 3$, mean volume was $6.89 \mathrm{~cm} 3$.

\section{Vancouver Scar Scale}

The assessment of scar was done according to the Vancouver Scar Scale (VSS). Also the complaints of patients for pain and pruritis in terms of VAS- Visual Analogue Scale (for a range of 1 to 10) were recorded.

\section{Table 4}

\begin{tabular}{|c|c|c|c|}
\hline $\begin{array}{c}\text { No of } \\
\text { patients }\end{array}$ & $\begin{array}{c}\text { VSS } \\
\text { (mean) }\end{array}$ & $\begin{array}{c}\text { VAS for Pruritis on scale 1- } \\
10 \text { (mean) }\end{array}$ & $\begin{array}{c}\text { VAS for Pain on } \\
\text { scale 1-10 } \\
\text { (mean) }\end{array}$ \\
\hline 107 & 7.61 & 4.2 & 1.8 \\
\hline
\end{tabular}


Pain was not a major complaint most of the patients complained of pruritis.

\section{DISCUSSION}

Keloids and hypertrophic scars are abnormal scars, precise etiologic factorsare elusive, with the exception of tissue trauma; however, keloids have been reported spontaneously also. Adverse wound healing characteristics, such as infection and excessive wound tension, are associated with keloids and hypertrophic scars. 3 In this study also the most common cause was trauma which was found in $27 \%$ patients followed by infection in $20.6 \%$ patients. Certain areas of the body such as the sternum, deltoid region of the upper arm, and upper back, have increased susceptibility to keloid formation. These areas are also subject to elevated levels of muscle and skin tension, which may explain their association with keloids. 3 In this study Pre sternum (57\%) was the most common site, followed by torso, back and extremities. The pathologic scar seems to have the same prevalence in both sexes. Hypertrophy is more common in young patients and that evolution seems to be longest in children. On the contrary, scarring often evolves more rapidly in elderly patients. 4 The literature has documented race as a risk factor for pathologic scarring, particularly keloids, with black patients bearing a 2-fold risk compared with Hispanic and Asian patients.4,5 These data suggest that genetics play an important role in the pathogenesis of scarring. 6,7 It seems that such local factors as burn depth, the presence of infection in the wound bed, and healing delay have a relevance. 8 In this study male to female ratio was found to be higher (1.74:1).

\section{CONCLUSION}

This was an epidemiological study, which was carried out in a tertiary teaching hospital of northern India. The keloids and hypertrophic scars are more common in young males and most common cause being trauma and most commonly affected site is Pre-sternum. Itching is a common complaint though localized pain was complained by a few patients only.

\section{Financial support and funding}

Nil

\section{Conflict of interest}

No conflict of interest

\section{References}

1. Atiyeh, B., Costagliola, M. and Hayek, S. (2005). Keloid or Hypertrophic Scar. Annals of Plastic Surgery, 54(6), 676-680.

2. AlibertJLM, Quelques recherché sur la cheloide, Men Soc Medicale d' Emulation 1917;8:744-52

3. Ogawa, R., Okai, K., Tokumura, F., Mori, K., Ohmori, Y., Huang, C., Hyakusoku, H. and Akaishi, S. (2012). The relationship between skin stretching/contraction and pathologic scarring: The important role of mechanical forces in keloid generation. Wound Repair and Regeneration, 20(2), 149-157.

4. Alster, T. and Tanzi, E. (2003). Hypertrophic Scars and Keloids. American Journal of Clinical Dermatology, 4(4), 235-243.

5. Bodokh I, Brun P. Treatment of keloid with intralesional bleomycin. Ann Dermatol Venereol1996;123:791-4

6. Castagnoli, C., Peruccio, D., Stella, M., Magliacani, G., Mazzola, G., Amoroso, A. and Richiardi, P. (1990). The HLA-DR $\beta 16$ allogenotype constitutes a risk factor for hypertrophic scarring. Human Immunology, 29(3), 229-232.

7. Alster, T. and Tanzi, E. (2003). Hypertrophic Scars and Keloids. American Journal of Clinical Dermatology, 4(4), 235-243.

8. Gangemi, E., Gregori, D., Berchialla, P., Zingarelli, E., Cairo, M., Bollero, D., Ganem, J., Capocelli, R., Cuccuru, F., Cassano, P., Risso, D. and Stella, M. (2008). Epidemiology and Risk Factors for Pathologic Scarring After Burn Wounds. Archives of Facial Plastic Surgery, 10(2). 